\title{
Clonal Immunoglobulin Gene Rearrangement
}

National Cancer Institute

\section{Source}

National Cancer Institute. Clonal Immunoglobulin Gene Rearrangement. NCI Thesaurus.

Code C36443.

A DNA sequence rearrangement that results in the creation of a novel immunoglobulin.

This process occurs during the differentiation of B-lymphocytes, such that individual B-

cell progenitors, and their descendents, express an identical antibody molecule. 